\title{
PODE O NATURALISMO REDUCIONISTA DE DAVID COPP ACOMODAR O REALISMO E O CONSTRUTIVISMO MORAL?
}

\author{
Evandro Barbosa
}

UFPel

\begin{abstract}
RESUMO: Segundo David Copp, o cenário moral requer a compreensão de três aspectos interrelacionados básicos: identificar a natureza dos juízos morais, especificar a justificação dessas decisões e determinar o papel da sociedade moral neste esquema. Para isso, o autor discute a necessidade de uma teoria cognitivista da linguagem normativa (standard based theory), assim como uma teoria da justificação dos códigos morais (society centered theory). O propósito deste artigo é analisar em que medida a teoria moral de Copp consegue acomodar a metodologia construtivista sobre as bases realistas de seu naturalismo moral sem desmantelar seu propósito naturalista de relacionar (e reduzir) propriedades morais à propriedades naturais.
\end{abstract}

PALAVRAS-CHAVE: naturalismo; construtivismo; realismo; justificação.

\begin{abstract}
According to David Copp, the moral landscape requires an understanding of three basic interrelated aspects: identifying the nature of moral judgments, specify the justification for these decisions and determine the role of moral society in this scheme. For this, the author discusses the necessity of a cognitive theory of language rules (Standard-Based Theory) as well as a justification of the theory of moral codes (Society-Centered Theory). The aim of this paper is to analyze if Copp' moral theory can accommodate the constructivist methodology on the realistic basis of moral naturalism without dismantling your intention of relating (and reduce) moral properties to natural properties.
\end{abstract}

KEYWORDS: naturalism; constructivism; realism; justification;

\section{Contextualização}

Atualmente, o naturalismo moral parece ser uma poderosa ferramenta para resolver o problema da justificação. Entre seus defensores, David Copp oferece sua proposta de Society-Centered Moral Theory como uma forma reducionista de naturalismo que relaciona realismo e construtivismo, embora, aparentemente, este pareça ser um ponto dissonante em sua obra que 


\section{Dossiê Naturalismo, Dissertatio - Volume Suplementar 02 | UFPel [2015]}

precisa ser esclarecido. Segundo o autor, o cenário moral requer a compreensão de três aspectos inter-relacionados básicos: identificar a natureza dos juízos morais, especificar a justificação dessas decisões e determinar o papel da sociedade moral neste esquema. Para isso, o autor discute a necessidade de uma teoria cognitivista da linguagem normativa (standard based theory), assim como uma teoria da justificação dos códigos morais (society centered theory).

Em 1995, David Copp escreveu a obra Morality, Normativity, and Society, na qual o autor faz uma defesa sistemática de sua posição filosófica como sendo naturalista, realista e construtivista. Posteriormente, em seu livro Morality in a Natural World (2007) ${ }^{1}$ ele revisa sua posição e explica porque seria melhor considerar sua teoria naturalista como não-construtivista, embora ele não seja definitivo nesse ponto. Embora sua posição sobre o tema tenha sofrido alterações e detalhamentos nesse meio tempo, o leitmotiv de sua teoria permaneceu intacto: a defesa de um naturalismo reducionista e realista em moral, relutante em ser ou não construtivista. O propósito deste artigo é analisar em que medida a teoria moral de Copp consegue acomodar a metodologia construtivista sobre as bases realistas de seu naturalismo moral sem desmantelar seu propósito naturalista de relacionar (e reduzir) propriedades morais a propriedades naturais. Para determinar esta relação, apresentarei os elementos centrais de sua teoria - em especial sua teoria cognitivista da linguagem normativa (standard based theory) e sua teoria da justificação dos códigos morais (society centered theory) a partir de sua Society-

\footnotetext{
1 Diz ele: "Uma importante distinção que eu preciso explicar é entre a versão construtivista da teoria apresentada em meu primeiro livro [Morality, Normativity, and Society] e a versão não construtivista que está presente nesta obra [Morality in a Natural World]. Eu acredito que a versão não construtivista é a mais preferível." (Introdução - tradução do autor) Essa dubeidade em sua teoria irá acompanhar nossa discussão. Recentemente, Copp escreveu um texto intitulado Is constructivism an alternative to moral realism? (2013), o qual é relevante do ponto de vista da sistematização da relação entre realismo e construtivismo em sua teoria, na medida em que afirma não haver contradição na aproximação entre ambos, desde que se determine com clareza suas definições.
} 
Centered Moral Theory. Posteriormente, partirei de definições amplas - que chamarei de definições lato sensu - de naturalismo, realismo e construtivismo ${ }^{2}$ para, então, determinar suas especificidades na teoria de Copp e identificar porque realismo e construtivismo não estão convincentemente ligados pelo elo naturalista.

\section{I - Naturalismo lato sensu e naturalismo moral}

Existe certa dificuldade em precisar o termo naturalismo entre os filósofos, pois a ampla variedade de definições acompanha a enorme gama de áreas de sua aplicação. A despeito disso, todos concordam com um elemento: todos os modelos de naturalismo rejeitam a possibilidade de entidades supernaturais ${ }^{3}$. Nesse sentido, o naturalista parte de uma posição metafísica de que todos os fatos, inclusive os fatos morais, são fatos naturais ${ }^{4}$. Harman define o naturalismo lato sensu da seguinte maneira:

Naturalismo filosófico é uma postura especial da concepção mais ampla da filosofia, na medida em que as questões e os métodos da filosofia são contínuos aos temas e métodos de outras disciplinas, incluindo especialmente as ciências naturais. A partir de uma perspectiva naturalista, filósofos produtivos são aqueles que (entre outras coisas) produzem frutíferas ideias teoréticas mais ou menos especulativos, sem distinção nítida entre tal teorização por membros de departamentos de filosofia e tal teorização por membros de outros departamentos. ${ }^{5}$

No âmbito normativo e metanormativo, o naturalismo é um rótulo normalmente utilizado para formas combinadas de naturalismo e realismo moral. Esta relação define a posição standard do naturalismo. Tal posição assume a estratégia metodológica do naturalista e a condição ontológica do

2 Como o autor não discorre longamente sobre o construtivismo, faremos uso das definições de Sharon Street, as quais Copp utiliza para determinar o tipo de construtivismo que defende.

${ }^{3}$ Cf. PAPINEAU, "Naturalism", Stanford Encyclopedia, 2015.

${ }^{4}$ Seguimos a definição de James Lenman sobre o que são fatos naturais: "Fatos naturais são entendidos como sendo fatos sobre o mundo natural, fatos do tipo que as ciências naturais intercambiam (trade)." (Moral Naturalism, Stanford Encyclopedia, 2006)

${ }^{5}$ HARMAN, 2012, p. 10. 


\section{Dossiê Naturalismo, Dissertatio - Volume Suplementar 02 | UFPel [2015]}

realista em moral como uma poderosa combinação tanto para a defesa de fatos morais objetivos, quanto para a explicação da relação entre propriedades morais e propriedades naturais. Nesse sentido, enquanto o não-naturalista pode apelar para entidade ou propriedades que considera como sendo não naturais para explicar o fenômeno moral, o naturalista não endossa um domínio de fatos não naturais ou supernaturais. Logo, quando buscamos justificar e analisar questões relacionadas ao valor moral e qual sua base de justificação, a resposta naturalista passa pela possibilidade de acomodar valores e obrigações morais sobre uma base científica ou naturalista do mundo. Sturgeon define a posição standard do naturalismo moral a partir de duas propriedades:

(a) propriedades éticas como a bondade das pessoas, traços de caráter e outras coisas como a correção ou incorreção das ações são propriedades naturais do mesmo tipo que as propriedades investigadas pelas ciências e (b) elas [propriedades éticas] são investigadas no mesmo sentido geral que nós investigamos as propriedades pela ciência. ${ }^{6}$

Não obstante, essa definição continua sendo ampla demais, pois dependerá de cada teoria determinar o que compreende por propriedade natural, qual o método de investigação e a definição de mundo natural. Como dito acima, devemos entender que esta é apenas a explicação standard do naturalismo, pois alguns de seus desdobramentos se estendem a construtivistas, expressivistas, relativistas e mesmo teóricos do erro. Tal é o alcance do naturalismo sobre as famílias de visões metaéticas. ${ }^{7}$ Entretanto, fica assegurado, assim como no naturalismo lato sensu, a firme convicção em rejeitar ou depender de crenças ou comandos supernaturais.

\footnotetext{
${ }^{6}$ STURGEON, 2006, p. 92.

7 Um exemplo disso é a posição relativista, a qual fala da relativização moral é dada pelas diferentes convenções sociais que estabelecem. $E$, dado que as convenções são assumidas como fatos sociais que pressupõe fato naturais, o relativismo poderia se enquadrar como uma forma de naturalismo. Porém, isso parece depor contra o eterno debate convention-versus-nature (Cf. STURGEON, p. 93) É isto que parece enfraquecer a posição realista de Copp ou, ao menos, não a torna um tipo de dogmatismo moral. É nisso que nos apegamos para contornar a aparente contradição entre definir realismo e construtivismo como uma posição defensável.
} 
Mais do que isso, o naturalismo em moral quer indicar que questões morais são explicadas da perspectiva de um mundo natural, o que lhe confere o ônus de explicar porque, ao reduzir valor e conhecimento moral a uma questão puramente científica, ele não inviabiliza a própria condição do mundo moral $^{8}$. No caso específico de Copp, a pressuposição de que existem fatos e proposições morais - sendo tais fatos e propriedades redutíveis a fatos e propriedades naturais - indicam uma dificuldade na relação entre naturalismo e construtivismo.

\title{
Naturalismo reducionista e não reducionista
}

Copp segue a definição standard de naturalismo, ou seja, ele endossa um tipo de realismo moral ao afirmar:

\begin{abstract}
Naturalismo moral sustenta que ao pensarmos coisas como moralmente corretas ou erradas, boas ou más, nós atribuímos propriedades morais para essas coisas - propriedades, como retidão moral e maldade, o bem e o mal. Isto pressupõe que tais propriedades existam e acrescenta que essas propriedades são propriedades naturais ordinárias do jardim do mundo propriedades que têm o mesmo estatuto metafísico e epistemológico básico que as propriedades de uma árvore poder ter folhas ou a propriedade de um de pedaço de papel poder ter o valor de uma nota de vinte dólares australiano. ${ }^{9}$
\end{abstract}

Nesse sentido, determinadas propriedades morais, tais como bondade, justiça e virtude, são propriedades naturais, por isso o naturalismo ético, embora seja uma espécie de realismo moral, dispõe de uma condição específica de admitir propriedades naturais e se distingue de outras formas de realismo. Como veremos adiante, sua proposta naturalista se distingue de

${ }^{8}$ Teóricos do comando divino (divine command theory) questionam exatamente este ponto, posto que 0 determinismo resultante desta posição naturalista inviabilizaria a condição de liberdade, arbítrio e responsabilidade do agente moral. A essa respeito, confira o voluntarismo teológico (Theological Voluntarism) de Philip L. Quinn em COPP, 2006, p. 63-90.

${ }^{9}$ COPP, 2007, p. 249. 


\section{Dossiê Naturalismo, Dissertatio - Volume Suplementar 02 | UFPel [2015]}

outras formas de realismo moral ao considerar que a propriedades morais são propriedades naturais. Por ora, o desafio naturalista é sustentar uma resposta positiva à questão sobre a existência de propriedades morais a partir de propriedades naturais, pois não parece claro como tais propriedades são relacionadas.

Diferente da ciência, em que propriedades naturais são observadas e explicadas de forma cada vez mais precisa e complexa, a ética parece um terreno obscuro quando tratamos de determinar propriedades morais, tais como erradeza. Vejamos a comparação. Do ponto de vista de ciência, podemos compreender com precisão como um assassinato ocorreu, determinando com precisão como o projétil de uma arma de fogo atravessou o corpo da vítima, como os seus órgãos foram afetados e o consequente óbito. Entretanto, se para a ciência criminal a causa mortis é suficiente para determinar o causador deste evento, cabe à ética determinar, para usar a afirmação de Hume, "onde

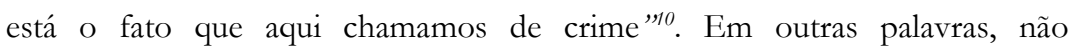
conseguiríamos atribuir a propriedade moral da erradeza para o assassinato e, sem ela, não seria possível atribuir culpa ou responsabilidade ao criminoso. Mas, este desafio de explicar como extraímos propriedades morais a partir de propriedades naturais tem resposta clara para o naturalista: não há dúvidas de que propriedades morais existem no mesmo sentido que propriedades naturais e, como estratégia, eles argumentam que os juízos morais sobre certo ou errado também são afirmações sobre o mundo. Logo, existem certas propriedades morais no mundo e podemos identificá-las assim como a ciência o faz com outros tipos de propriedades naturais.

A questão acerca da relação entre propriedade morais e propriedades naturais divide os naturalistas. A definição latu sensu do naturalista não exige a existência de propriedades morais como uma natureza única ou sui generis,

\footnotetext{
${ }^{10} \mathrm{HUME}$, Apêndice, 1, 6, 16.
} 
apenas que há uma conexão delas com outras propriedades. E é exatamente ao requisitar esta conexão entre propriedades naturais e propriedades morais que os teóricos se dividem em não reducionistas e reducionistas. Os teóricos morais não-reducionistas, entre eles o realismo de Cornell com Brink, Sturgeon e Boyd, ${ }^{11}$ afirmam que propriedades morais são irredutíveis a propriedades naturais, embora reconheçam que julgamentos morais funcionam em consonância a explanações sobre o mundo. Por sua vez, o reducionismo moral (moral reductionism) afirma que “(...) as propriedades morais são propriedades que podem ser identificadas com propriedades não-morais, onde tal identificação exige-nos escolher a partir de fora exatamente o que são estas outras propriedades as propriedades morais."12 Em suma, o reducionista assumirá que propriedades morais existem no mundo, e este mundo é natural, por isso parece sensato pensar que existe um link entre mundo natural e mundo moral.

Agora, se deslocarmos o eixo da discussão sobre a justificação da moral para a natureza das propriedades morais, evidenciaríamos um problema anterior a esta relação. A saber, se quisermos definir a relação reducionista entre propriedades morais e naturais, precisamos compreender o que é uma propriedade natural ${ }^{13}$. Copp dirá que uma propriedade natural deve ser entendida como uma propriedade empírica, ou seja, “(...) uma propriedade é natural, se e somente se qualquer proposição sintética que possa ser conhecida a partir dessa instanciação, puder ser conhecida empiricamente." ${ }^{14}$ Logo, o

11 Segundo Jackson, o realismo de Cornell possui três características: "(a) propriedades éticas são idênticas a propriedades descritivas; (b) as sentenças relevantes de identidade são necessárias a posteriori e (c) nenhuma análise dos predicados e sentenças éticas em termos descritivos é possível." (JACKSON, 1998, p. 144)

12 KIRCHIN, 2012, p. 49.

${ }^{13}$ Copp identifica quatro estratégias para responder a esta questão e resolver o problema da open question argument de Moore. São elas: (A) proposta reducionista (reductionist proposals), (B) definição ostensiva (ostensive definitions), (C) definição metafísica (metaphysical definitions) e (D) definição epistêmica (epistemic definitions). Cf. COPP, 2007, p. 36-39.

${ }^{14}$ COPP, 2007, p. 36. 


\section{Dossiê Naturalismo, Dissertatio - Volume Suplementar 02 | UFPel [2015]}

naturalismo seria definido em termos do que podemos ou não conceber a partir da experiência. Kirchin chama de naturalismo reducionista sintético ${ }^{15}$ modelos como o de Copp, tendo em vista que poderíamos reduzir propriedades morais a propriedades naturais de um modo específico (no caso, a propriedades empíricas). De acordo com essa visão, nós conseguiríamos mapear o mundo natural ou descobrir os mapeamentos disponíveis deste mundo, os quais nos permitiriam identificar a presença de propriedades morais no mundo através de uma investigação empírica. Se assim for, parece que existir um sub-set de propriedades naturais dentro do set natural, assim como as ciências possuem um sub-set de propriedades naturais avaliáveis.

\section{II - A teoria moral centrada na sociedade de Copp Constrição normativa e the picture of morality}

Questões morais são questões Janus-faced para Copp, pois toda vez que emitimos um juízo de valor sobre determinadas questões, tendemos a assumir nossas convicções morais como crenças 'semelhantes' a crenças sobre cadeiras, mesas e livros. Em outras palavras, intuitivamente nós as tomamos como verdadeiras. Paralelamente, enfrentamos o outro lado da moeda quando consideramos a existência de convicções morais enquanto uma verdade

\footnotetext{
$15 \mathrm{KIRCHIN}, 2012$, p. 69. Kirchin ainda distingue o reducionismo naturalista analítico, que acredita na possibilidade reducionista como a posição sintética, porém ela substitui o mapeamento através de métodos não-empíricos por uma análise conceitual. Neste ponto, existiria uma dificuldade em estabelcer o link entre propriedade moral e propriedade natural, especialmente para o reducionista analítico. Sua estratégia é realizar uma network analysis, ou seja, relacionar conceitos morais a outros conceitos também morais e explicar como tais conceitos se identificam individualmente com conceitos naturais. Por exemplo, o conceito de bondade é explicado em um conjunto de proposições onde seu uso é relevante, demonstrando o papel que bondade tem nesse esquema conceitual em termos morais. 0 próximo passo é demonstrar, como fizeram Moore e Hare por exemplo, o conceito de Bom como nosso conceito moral central. Por sua vez, nós podemos remover todos os demais termos avaliativos e normativos, explicando o bom a partir de propriedades naturais que descrevem a bondade. Dessa forma, poderíamos reinterpretar como tais propriedades naturais desempenham a função de correto porque desempenham o papel da bondade. Com isso, temos uma âncora em nosso sistema a partir do qual temos uma propriedade natural que desempenha o papel da bondade. Reduzimos, assim, propriedades morais a propriedades naturais.
} 
duvidosa, na medida em que ordinariamente tendemos a observar nossas convicções morais como distintas de crenças sobre cadeiras, mesas e livros. Em geral, esta é uma dicotomia que persegue nossos questionamentos metaéticos.

Por isso, a discussão sobre normatividade envolve o desafio metaético de desenvolver uma teoria da natureza dos juízos morais, ao mesmo tempo em que precisamos discutir as condições de verdade de tais juízos. A questão central para Copp é demonstrar a relação entre propriedades naturais e propriedades morais, explicando como propriedades naturais podem ser propriedades normativas. ${ }^{16} \mathrm{~A}$ alternativa mais segura, então, seria nos comprometermos com um realismo através de um modelo naturalista, posto que “(...) nossas crenças morais atribuem características morais sobre coisas, características tais como bondade e correto, e que tais características são características naturais, relevantemente similares a propriedades ordinárias das coisas, tais como as propriedades meteorológicas e econômicas." 17

Nesse momento, Copp lança mão da chamada teoria moral centrada na sociedade (Society-Centered Moral Theory) ${ }^{18}$ como exemplo de naturalismo moral. Segundo o autor, toda sociedade precisa de um código moral social que garanta a convivência equilibrada entre os indivíduos, afinal são elas que

\footnotetext{
${ }^{16}$ Além disso, Copp assume o que chama de internalismo normativo, segundo o qual se propriedades morais existirem elas são necessariamente normativas, ou seja, uma propriedade só poderá contar como propriedade moral se ela for normativa. Logo, a insuficiência em explicar o normativo implica na insuficiência de explicar propriedades morais. Copp segue com uma crítica ao internalismo motivacional, chamando a atenção para a necessidade de explicar o link entre crença moral e motivação. Segundo ele, apesar de defender um modelo de internalismo normativo para questões de julgamento moral, sua teoria endossa um tipo de externalismo motivacional, embora ele reafirme a distinção entre seu naturalismo e o realismo de Cornell que também emprega um tipo de externalismo motivacional. 0 problema de Cornel, segundo Copp, não está no problema da motivação, mas na insuficiência sobre a explicação da normatividade das propriedades morais.

17 COPP, 2007, p. 02.

${ }^{18}$ Copp define Sociedade da seguinte maneira: "Uma sociedade é uma população multi-geracional de pessoas que se estende temporalmente, abraçando uma rede relativamente fechada de relações de amizade, afeto, parentesco e cooperação na reprodução e limitado pela mais ampla fronteira de um sistema distinto e saliente de interação instrumental que facilita a busca das necessidades da vida e as prioridades da cultura do grupo." (COPP, 2007, p. 22)
} 


\section{Dossiê Naturalismo, Dissertatio - Volume Suplementar 02 | UFPel [2015]}

orientam as nossas relação e permitem a cooperação entre os seus membros ${ }^{19}$. Se quisermos compreender a dinâmica presente neste cenário moral (picture of morality), precisamos compreender três aspectos básicos inter-relacionados para a determinação deste código moral social: (i) identificar a natureza da moralidade (dos juízos morais), (b) determinar sua justificação e (iii) discutir o papel da sociedade neste esquema e na determinação dos dois primeiros elementos.

Neste enquadramento, qualquer tentativa de harmonizar os elementos deste cenário em uma teoria consistente exigiriam explicar o normativo. Esta é a chamada constrição normativa, segundo a qual “(...) uma teoria metaética adequada deve explicar no que consiste a normatividade dos julgamentos morais" 20 , quer dizer, antes mesmo de discutirmos o peso moral de determinadas proposições, as propriedades que a compõe devem ser normativas. Este quadro moral possui dois componentes centrais em suas fórmula. Precisamos de uma teoria cognitivista da linguagem normativa, quer dizer, uma (a) standard based theory - SBT que ofereça um modelo geral das condições de verdade para as proposições normativas. Em outras palavras, uma proposição moral será verdadeira se e somente se a regra ou padrão à qual se refere estiver justificada. Além disso, carecemos de uma teoria da justificação dos códigos e padrões morais, o que Copp chama de (b) society-

\footnotetext{
${ }^{19}$ Segundo Copp, a moralidade é um conjunto útil de regras sociais se pensarmos em termos de função da moralidade. Nesse sentido, proposições morais básicas sobre certo e errado - por exemplo, mentir é errado! - será verdadeira se e somente se servir da melhor forma ao seu propósito de organização social. Se tomarmos a proposição moral básica de que mentir é errado, socialmente nós poderíamos estabelecer a norma de proibição da mentira. Nesses termos, moralidade é o conjunto útil de regras sociais, ou seja, crenças morais são simples ficções úteis.

${ }^{20}$ COPP, 2007, p. 03. Por exemplo, há uma diferença considerável do ponto de vista normativo entre 0 juízo 'nós devemos cuidar de nossos pais doentes' e a afirmação 'sempre que posso eu cuido dos meus pais doentes'. No primeiro caso, empreendemos uma questão avaliativa que decorre da condição normativa do deve, o que distingue-a da segunda proposição, em que sempre que posso não indica um deve ou obrigação normativa, ela é apenas uma descrição sobre como ajo cotidianamente. No caso do realista, sua preocupação está no modo como explicamos proposições normativas que empregam 0 conceito dêontico de dever, informando que deve e sempre que posso indicam propriedades distintas.
} 
centered theory - SCT, afinal as sociedades precisam de códigos sociais morais, ou seja, precisamos que certos padrões estejam justificados para que, por sua vez, afirmações morais possam estejam justificadas e possam ser consideradas verdadeiras. Vejamos.

A Standard-based theory (SBT) não oferece um tipo de justificação de um código moral pela simples derivação de normas básicas a partir de determinada visão moral. Pelo contrário, um código moral está justificado se e somente se determinada sociedade é racional para escolher este código moral social21 ${ }^{21}$ Esta característica endossa a necessidade de justificação dos juízos morais a partir de uma teoria cognitivista da linguagem normativa (standar-based theory), a qual oferece um modelo geral das condições de verdade para as proposições normativas. Por isso, faz-se necessário analisar as condições de justificação, pois é nesta discussão que o viés construtivista de sua teoria irá se estabelecer ${ }^{22}$.

Copp estabelece uma distinção entre proposições morais do tipo 'mentir é errado' e standards morais tal como o standard que proíbe a mentira e que pode ser expresso no imperativo: "Não minta!" Nesse sentido, standards são o conteúdo semântico expresso por imperativos, embora eles mesmos (os standards) não sejam crenças e muito menos representem o mundo desta ou daquela maneira. Esta é a teoria cognitivista de linguagem normativa proposta por Copp:

O esquema pretende ser aplicável para delimitar as condições de verdade de qualquer tipo de proposição normativa. O esquema diz que uma (pura e básica) proposição normativa do tipo K é verdadeira se e somente se um standard correspondente do tipo $\mathrm{K}$ possua o status de fundamentação da verdade K-relevante. ${ }^{23}$

${ }^{21}$ Esta visão é apresentada no texto de 1995, porém parece ser abandonada na obra de 2007 quando Copp identifica uma dificuldade em sua teoria definir racionalidade. Mais a frente, esta discussão será retomada para distinguir os traços naturalista e construtivista de sua teoria.

${ }^{22}$ Cf. COPP, 1995, Introdução.

${ }^{23}$ COPP, 2007, p. 14. 


\section{$\underline{\text { Dossiê Naturalismo, Dissertatio - Volume Suplementar } 02}$ | UFPel [2015]}

Partindo desta pressuposição, Copp irá propor SBT como o esquema capaz de explicar as condições de verdade das proposições morais em termos de status relevantemente correspondente aos padrões morais. Considere o exemplo da etiqueta e a necessidade de standards que sustentem suas regras do tipo 'não fale de boca cheia' ou 'não interrompa conversas alheias'. Tais regras apenas se sustentam se existir um correspondente (K-relevante) que indique que é grosseira falar de boca cheia ou que não é adequado intrometer-se na fala de outros sem ser convidado. O mesmo ocorreria na dimensão moral, pois se aplicarmos o procedimento $S B T$ descobriremos que uma proposição moral será verdadeira se e somente se existir um standard correspondente, o qual, por sua vez, deve ter uma condição de verdade moralmente relevante. E esta condição de ser moralmente relevante é central para compreendermos qual status um standard moral precisa ter na medida em que a proposição moral for verdadeira.

Nesse sentido, deverá existir alguma condição de verdade fundamental (truth-grounding status) que garanta a verdade de proposição moral correspondente. Neste jogo entre standards e proposições morais, SBT se propõe oferecer as garantias de verdade da proposição a partir de um teste de seu standard correspondente. Logo, se este estiver justificado, a proposição moral correspondente também estará. ${ }^{24}$

(b) Society-centered theory (SCT). Códigos morais sociais podem ser dados a partir da Society-centered theory (SCT), os quais, embora necessários, podem variar de sociedade para sociedade. Com a ideia de Society-based theory, Copp apenas indicou para a necessidade de justificação de standards, porém não indicou em que consiste tal justificação. Agora, SCT irá oferecer o procedimento através do qual nós poderemos apresentar uma teoria da justificação dos códigos e padrões morais. De acordo com a SCT,

${ }^{24}$ Cf. COPP, 2007, p. 15. 
(...) uma proposição moral básica é verdadeira se e somente se um correspondente padrão moral está incluído nela ou implícito pelo código moral a circulação destes na sociedade relevante permitiria a sociedade melhor servir seus necessidades básicas do que seria pela circulação de outros conjuntos de regras e seria melhor do que se nenhum conjunto de regras circulasse na sociedade. ${ }^{25}$

Nesse caso, os padrões morais precisam ter certo status de fundamentação de verdade que seja relevante. Tal status é a sua capacidade de ser moralmente autoritativo, ou seja, possuir força para nos obrigar. Interessanos saber se SCT pode explicar o status autoritativo da moralidade destes códigos, pois esta é a sua condição relevante de fundamentação da verdade moral.

Há uma preocupação em identificar o que é uma afirmação normativa, já que muitas são as suas variantes, tais como afirmações normativas sobre questões jurídicas, morais, epistemológicas, de etiqueta, etc. Além disso, elas diferem de afirmações não normativas do tipo 'a neve é branca' ou 'meu gato é gordo', pois estas não apresentam um standard correspondente do ponto de vista normativo. Através da SBT, Copp define que as afirmações normativas indicam para determinados standards. No âmbito moral, tais standards possuem um status apropriado correspondente a este âmbito, assim como existem standards correspondentes para o âmbito jurídico, epistemológico, entre outros (lembre-se do exemplo da etiqueta), o que nos leva inferir que a natureza deste status depende do âmbito de sua aplicação. No caso âmbito moral, o status das afirmações neste contexto é ele próprio normativo, por isso proposições morais serão verdadeiras se e somente se os standards morais correspondentes estão apropriadamente justificados. ${ }^{26}$ Logo, há uma normatividade intrínseca a cada proposição moral, ou seja, elas

${ }_{25}$ COPP, 2007, p. 17. As necessidades básicas de uma sociedade envolveriam integridade física, integridade cooperativa e relações pacíficas e cooperativas com outras sociedades. (COPP, 2007, p. 17) ${ }^{26}$ COPP, 1995, p. 03. 


\section{Dossiê Naturalismo, Dissertatio - Volume Suplementar 02 | UFPel [2015]}

naturalmente nos obrigaram no entender de Copp. Por sua vez, SCT está preocupada em explicar as condições sob as quais os padrões morais deveriam ser relevantemente justificados, o que, no caso de Copp, implica em afirmar que determinado código moral só se justifica para uma sociedade se esta sociedade racionalmente escolhe e endossa tais regras morais.

Sendo assim, será pela combinação de SBT e SCT que Copp espera justificar seu naturalismo realista. Como ele mesmo informa, tais componentes poderiam se combinar distintamente quando separados, ou seja, a society-centered theory poderia endossar uma posição não-cognitivista, assim como a standardbased theory serviria para justificar outros modelos cognitivistas supra ou não naturalistas. ${ }^{27}$ Contudo, a teoria moral centrada na sociedade é, no entender do autor, uma poderosa combinação entre standard-based theory e society-centered theory para a resolução dos problemas de epistemologia e de justificação moral, respectivamente. Através dela, seríamos capazes de explicar o conteúdo normativo das proposições morais e determinar a natureza destas proposições. Como vimos, o naturalismo de Copp nos leva a relacionar propriedades morais e naturais através de uma explicação sobre a normatividade. E, como veremos, SBT indica para uma condição cognitivista e realista de sua teoria, porém será especialmente em SCT que encontraremos elementos para uma interpretação construtivista de sua teoria.

\section{III - Construtivismo e realismo moral Construtivismo moral}

Passamos agora a identificar construtivismo e realismo em suas versões lato sensu. O construtivista moral lato sensu afirma que fatos ou verdades morais são construídos, quer dizer, normas morais são verdades produzidas (true made) a partir de um conjunto de crenças (beliefs) que são nossas evidências em ética. David Brink, que é um realista moral, assim define o construtivismo:

${ }^{27}$ Cf. COPP, 1995, p. 06. 


\section{Evandro Barbosa}

\section{Construtivismo moral:}

(1) Existem fatos ou verdades morais;

(2) Tais fatos ou verdades são constituídas por evidência deles. $^{28}$

Evidentemente, esta definição está contaminada pelo crivo realista do autor, porém o núcleo do modelo construtivista de que valores são construídos e não descobertos está preservado. Por sua vez, quando Copp discute o problema do construtivismo, ele utiliza a terminologia de Sharon Street $^{29}$ para distingui-lo em (a) visão restritivista, segundo a qual o construtivismo é uma questão de ética normativa substantiva, e (b) visão metaética, para a qual o construtivismo precisa dar conta das questões centrais de segunda ordem. Street assim define o construtivismo restritivista:

(a) A visão construtivista restritivista em ética especifica um conjunto restrito de reivindicações normativas e diz que a verdade das afirmações abrangidas neste conjunto consiste é constituído por afirmações implicadas a partir do ponto de vista prático, sendo o ponto de vista prático dado por alguma caracterização substantiva. ${ }^{30}$

Por se tratar de uma questão de primeira ordem, a proposta restritiva tem o objetivo de dar conta da verdade de um subconjunto limitado de reivindicações normativas. Nesse sentido, fala-se em um conjunto específico de reivindicações normativas substantivas escolhidas pelo proponente da teoria, ou seja, os teóricos morais. De um modo geral,

${ }^{28}$ BRINK, 1989, p. 20. Brink afirma que existem duas formas de construtivismo nesses termos: (a) há o construtivismo relativista e (b) há o construtivismo não-relativista.

${ }^{29}$ Confira seu texto What is constructivism in ethics and metaethics? (2010).

30 STREET, 2010, p. 08. De modo similar, Darwall, Railton e Gibbard (2013) corroboram com esta visão: “(...) o construtivista é um procedimentalista hipotético. Ele endossa um procedimento hipotético que determina quais os princípios que constituem os padrões válidos da moralidade. Esse procedimento pode referir-se também, digamos, a uma decisão a respeito do código moral que deve ser apoiado em uma sociedade. Um procedimentalista mantém, então, que não há fatos morais independente da descoberta de que certo procedimento hipotético teria tais e tais resultados." (p. 45) 


\section{Dossiê Naturalismo, Dissertatio - Volume Suplementar 02 | UFPel [2015]}

este tipo de construtivismo afirma que as verdades das afirmações normativas decorrem do fato de que tais afirmações serão talhadas a partir de um ponto de vista prático pré-determinado ${ }^{31}$, tal como o procedimento da Society-Centered de Copp ou mesmo a posição original de John Ralws. Esta visão é endossada por Darwall quando afirma que este tipo de construtivismo dá conta apenas dos problemas de primeira ordem e, por isso, quando confrontado com outros modelos normativos, ele precisa explicar porque deve ser estabelecer em detrimento de outros modelos. Em suma, a visão construtivista se distingue das demais visões éticas ao dar prioridade à relação que se estabelece entre determinado procedimento e o resultado correto/verdadeiro do seu uso.

Dado seu caráter restritivista, questões metaéticas seguem em aberto nesta visão de construtivismo, por isso a sugestão de Street é de que abandonemos a caracterização procedimental e assumamos o ponto de vista prático como determinante. Em suma, ela afirma que o construtivismo metaético é melhor, uma vez que a força da argumentação não estaria propriamente no procedimento, mas no ponto de vista do agente que endossa certos valores, ou seja, o ponto de vista prático sobre o que fazer ou não dentro deste procedimento.

Street propõe, então, que se substitua o rótulo procedimental do construtivismo - representado pelo slogan nenbuma verdade normativa independente do procedimento - pela noção de construtivismo de um ponto de vista prático, aqui representado pela ideia nenbuma verdade normativa independente do ponto de vista prático. Com isso, poderemos afirmar que não existem padrões de correção no domínio normativo exceto a partir de algum

\footnotetext{
${ }^{31}$ Nas palavras de Street, "(...) de acordo com a caracterização procedimental, a visão construtivista compreende verdade normativa não como uma mera descoberta por (uncover by) ou coincidindo com (coinciding with) o resultado de determinado procedimento, mas como constituída (constituted) por emergência pelo surgimento deste procedimento." (STREET, 2010, p. 03)
} 
lugar, quer dizer, “(...) do ponto de vista de alguém que já aceita este ou aquele juízos normativos, i. e., ponto de vista de uma criatura que valora." 32 Em outras palavras, dado que o construtivismo metaético tem sua base no ponto de vista prático (practical standpoint characterization), tais normas não são definidas pelo procedimento propriamente, mas pelos agentes que criam os juízos morais.

Pautado nesta distinção, Copp afirma que sua SCT - que ele chama de teoria original por ter sido elaborada primeiro (1995) - é construtivista, porém no desenvolvimento de sua teoria ele abandona essa posição ao dizer que SCT - agora chamada por ele de teoria básica (2007) - pode prescindir destes contornos construtivistas. No seu entender, a teoria original é construtivista na media em que

(...) está comprometida com a tese de que as proposições morais são verdades construídas (made true) por um tipo relevante de endosso a partir de um ponto de vista preferencial. Podemos dizer que uma teoria construtivista define que a função do endosso é determinar um tipo especifico de entrada (input) e produzir proposições morais (ou proposições morais de um determinado tipo) como saída (output). Uma teoria construtivista sustenta que existe uma função de endosso $\mathrm{F}$ tal que uma proposição moral (do tipo $\mathrm{K}$ ) é verdadeira apenas no caso em que (e porque) $\mathrm{F}$ produz a proposição como saída (output) de uma entrada relevante (imput). Se definirmos que esta é a doutrina central do construtivismo, então a teoria original é construtivista. ${ }^{33}$

Por sua vez, a teoria básica de SCT não é construtivista porque a verdade de uma proposição moral depende tão somente de “(...) qual sistema de normas poderia melhor servir às necessidades da sociedade em questão, e isso é uma questão que independe de endosso (endorsement-independent matter)." 34 Por não precisar do endosso, a teoria básica não precisaria pressupor uma teoria da racionalidade prática para o problema da

\footnotetext{
32 STREET, 2010, p. 05.

${ }_{33}$ COPP, 2007, p. 19.

${ }^{34}$ COPP, 2007, p. 20.
} 


\section{Dossiê Naturalismo, Dissertatio - Volume Suplementar 02 | UFPel [2015]}

justificação. Sendo assim, sem a necessidade de um endosso racional, a teoria naturalista de Copp teria o seguinte formato: de um lado, teríamos o SCT original como uma forma de construtivismo restritivista à medida que necessita de um procedimento onde agentes racionais endossam e, consequentemente, constroem o social moral code; de outro, a teoria SCT básica não lançaria mão de uma teoria da racionalidade e não reduziria o problema da normatividade da moralidade a um simples questão de teoria da escolha racional. ${ }^{35}$ Apesar desse abandono da teoria original, Copp não explica exatamente porque sua teoria deixa de ser construtivista, pois SCT parece ser um tipo restritivista de construtivismo e, embora possa não centralizar a justificação na racionalidade dos agentes envolvidos, ainda assim precisa explicar a passagem de propriedades naturais (input) para propriedades morais (output). Talvez essa explicação possa ser dada pela definição realista de sua teoria. Vejamos.

\section{Realismo moral}

Em sua obra Moral realism and the foundations of ethics (1989), David Brink oferece uma definição ampla de realismo moral.

\section{Realismo moral:}

(1) Existem fatos morais ou verdades morais;

(2) Tais fatos são independentes; 36

Conjuntamente (1) e (2) constituem o núcleo duro das teorias realistas lato sensu. Em termos de ontologia moral, esta definição é realmente ampla, a tal ponto que antirrealistas ${ }^{37}$ poderiam concordar com (1) e os

\footnotetext{
${ }^{35}$ Cf. COPP, 2007, p. 21.

${ }^{36}$ BRINK, 1989, p. 16

37 O exemplo clássico desta dissolução do núcleo realista é o antirrealismo de John Mackie (1977), embora sua crítica pareça dar conta apenas de tipos específicos de realismos. Sua posição é claramente antirrealista na medida em que endossa três teses básicas de ontologia moral: a. Não existem valores morais objetivos (fatos morais) independente da mente do sujeito; b. Os juízos morais são independentes dos valores morais objetivos (se é que eles existem); c. Os valores morais objetivos são derivados dos juízos morais. Como resultado, sua proposta assume a forma de uma teoria do erro
} 
próprios realistas divergiriam - como o fazem atualmente - sobre onde encontrar (2). Para esclarecer esse ponto, Copp tomando as premissas (1) e (2) como ponto de partida, mas especifica o realismo a partir de cinco características, distinguindo-o em realismo básico (basic realism) e realismo de ordem independente (stance-independent):

\section{Realismo básico}

1. Existem propriedades morais;

2. Propriedades morais possuem a mesma

natureza básica de outras propriedades, inclusive propriedades não-normativas;

3. Algumas propriedades são instanciadas, ou seja, algumas ações são certas ou erradas (existe fato moral);

4. Predicados morais são usados para atribuir propriedades morais (Ex. Predicado errado é usado para a atribuição da propriedade moral de 'ser errado' sobre determinada ação. Nesse caso, predicados morais não se distinguem de um modo especial (sui generis) dos predicados descritivos ordinários).

5. Afirmações morais expressam crenças comuns que tem a mesma natureza básica de outras crenças. ${ }^{38}$

ao informar o equívoco de se pressupor que ao enunciar juízos morais estaríamos necessariamente pressupondo propriedades morais objetivas. Essa pressuposição é um erro. Para tanto, Mackie apela para os famosos argumentos da relatividade e da estranheza. O primeiro (the argument from relativity) oferece uma apoio indireto ao ceticismo de segunda ordem ao confirmar a existência de juízos morais discordantes e antitéticos, os quais derivam de seus respectivos contextos e tempo. 0 segundo argumento (the argumento from queerness) está dividido em duas partes: o elemento metafisico, o qual indica que "(...) se existissem valores objetivos, deveria existir também entidades, qualidades ou relações de natureza muito estranhas, inteiramente distintas de qualquer outra realidade do universo." (MACKIE, 1977, p. 43). Na mesma medida, o elemento epistemológico é a discussão sobre a necessidade de existir uma faculdade peculiar da percepção moral ou da intuição - diferente de qualquer faculdade ou percepção comum de conhecer as demais coisas - que nos permitiriam acesso a tais valores objetivos.

${ }^{38}$ COPP, 2014, p. 121-122. Segundo Copp, os antirrealistas não-cognitivistas poderiam concordar com as tese de (1), (2), (3) e (4), porém o ponto (5) seria determinante para distinguir sua posição. A tese (5) de que propriedades morais compartilham o mesmo status metafísico de qualquer outra propriedade, independente de seu status, distinguiria a posição de Copp de versões deflacionadas de antirrealismo e não-cognitivismo. 


\section{Dossiê Naturalismo, Dissertatio - Volume Suplementar 02 | UFPel [2015]}

O realismo de ordem independente (stance-independent) acrescenta uma sexta (6) ${ }^{39}$ tese de que determinados fatos morais existem de forma independente da mente do agente (mind-independent). Este problema de ontologia moral interessa-nos para a discussão acerca do naturalismo, pois o possível caráter construtivista da teoria de Copp se sustentaria sobre as bases de um realismo e de um cognitivismo morais. Estabelecemos, assim, as definições amplas e restritas de construtivismo e realismo, restando, agora, discutir como esta relação se estabelece no seio naturalista.

De modo resumido, Copp irá argumentar que o construtivista metaético pode aceitar o pacote das 5 teses do realismo básico, porém cairia em contradição se aceitasse a tese 6 (stance-independent). No caso da tese (1) acerca da existência de propriedades morais, podemos dizer que o construtivista lato endossaria a existências destas propriedades, embora ele não as reduziria a propriedades naturais, nem iria buscá-las em uma ordem independente de valores. Nesse sentido, a adesão construtivista a esta tese não o torna um reducionista naturalista. Para (2), o construtivista também pode anuir que existe esta relação entre as propriedades morais e naturais, como no caso naturalista, porém com o seguinte esclarecimento: propriedades nãomorais, a partir do momento em que fazem parte do procedimento construtivista, serão interpretadas como propriedades morais, o que não parece ser um problema ao naturalista. ${ }^{40}$ Quanto a tese (3), o construtivista não vê problemas em admitir a existência de propriedades instanciadas, desde que elas sejam resultado do procedimento de construção, ou seja, sejam criadas por evidência deles. No que diz respeito a tese (4), o construtivista - especialmente o de viés restritivista - afirma que os predicados seria ordinários tão somente

\footnotetext{
${ }^{39}$ Na obra de 2007, Copp tem outra definição da sexta tese: "(6) Propriedades morais são propriedades naturais." (COPP, p. 10)

40 São exemplos desta defesa o naturalismo reducionista do próprio Copp e de Peter Railton, além de algumas vertentes de neoaristotelismo e pós-positivismo. Cf. DARWALL, GIBBARD, RAILTON, 2013, p. 11.
} 
até entrarem no procedimento. A partir desse ponto, eles passariam a ser predicados morais não redutíveis a simples verificação científica. O exemplo utilizado por Copp é afirmar que o predicado erradeza é usado para a atribuição da propriedade moral ser errado à ação $x$, sendo que tal predicado não desfrutaria de qualquer condição sui generis para sua existência. Esta discussão está diretamente associada a tese (5), uma vez que o construtivismo não precisaria negar que o estado mental do agente reduz asserções normativas a crenças ordinárias, na medida em que o estado mental do agente é de valoração e difere asserções morais de simples crenças ordinárias. Nesse sentido, as crenças não estariam reduzidas apenas às suas condições de verdade, pois o construtivista as assumiria como evidências apenas em um primeiro momento, quer dizer, antes de entrar no jogo procedimental. ${ }^{41}$ No exemplo acima, o construtivismo concordaria com a aplicação do predicado errado em proposições do tipo torturar é errado!. Ao fazê-lo, atribuiríamos a propriedade moral erradeza à tortura, muito embora esta propriedade preserve sua condição de ser uma crença com valor epistêmico.

\section{Tese (06) - O problema do realismo moral mind-}

\section{independence}

Como vimos, as teses realistas de (1) a (5) do chamado realismo básico podem ser endossadas pelo construtivista, mas o que dizer da tese (6) que defende uma ordem independente de valor e um tipo de realismo moral independente (Independent Moral Realism)? ${ }^{42}$ Sem dúvida, a grande restrição para

\footnotetext{
${ }^{41}$ Hare chama a atenção para o descritivismo ético, o que incorreu no que Austin chamou de "falácia descritivista". Cf. HARE, 2003, p. 71-94.

42 Kirchin define esta posição da seguinte maneira: A existência de propriedades morais e razões morais é uma questão independente da mente (mind-independent). Ou seja, a existência de tais propriedades e razões não é Dependente sobre o que seres humanos - quer individual quer coletivamente - pensam, desejam, estão empenhados em, desejam para, etc. Da mesma forma, o tipo ou caráter de valor ou razão que eles são - por exemplo, bondade e gentileza - é uma questão independente da mente (mindindependent)." (2012, p. 22)
} 


\section{Dossiê Naturalismo, Dissertatio - Volume Suplementar 02 | UFPel [2015]}

a relação entre realismo e construtivismo na teoria naturalista de Copp passa por esta sexta tese. Em um espectro amplo, o realismo moral independente (IMR) é um tipo de defesa ontológica sobre a existência de um fato ou verdade moral independente, ou seja, dado fora dos estado mentais dos agente morais. Essa forma robusta de realismo moral, em que determinado fato ou verdade moral parece resistente a possíveis distorções dadas pela interpretação do agente - inviabilizaria a possibilidade de um construtivismo moral que admita que fatos ou verdades morais existem e são construídos a despeito de um indivíduo ou grupo social. Com isso, o problema mind-(in)dependence distinguiria defensores do realismo (IMR) e construtivismo lato sensu:

Realismo IMR:

(1) Existem fatos ou verdades do tipo $x$, ou (2) tais fatos ou verdades existem independetemente da evidência deles.

Construtivismo afirmaria (l) e negaria (2).

Construtivismo:

(1) Existem fatos ou verdade do tipo $x$, e (2) tais fatos ou verdade são constituídos a partir da evidências deles.

Construtivismo endossaria e o realismo negaria que os fatos ou verdades em questão são constituídos a partir de nossas evidências deles. ${ }^{43}$

Em um versão resumida, poderíamos dizer que os fatos são evidenceindependent e as verdades morais são evidence-independent para os defensores da tese (6). Mas, o que é exatamente esta independência? Brink nos sugere três tipos: independência causal, independência metafísica e independência conceitual ${ }^{44} \mathrm{~A}$ independência causal seria defendida por modelos de realismo científico ao afirmar que objetos como portas e paredes existem como causalmente independentes dos estados mentais do seu criador. No caso do realista moral, sua preocupação é com um tipo de independência conceitual (tal

\footnotetext{
${ }^{43}$ BRINK, 1989, p. 16.

${ }^{44}$ Cf. BRINK, 1989, p. 15.
} 
como Moore ao tentar isolar o Bom de nossas definições e enquadramentos), ou mesmo a independência metafísica como prega o intuicionismo moral platonista. Nesse sentido, independência conceitual ou metafísica opera sobre o plano de uma dicotomia fato-valor. Em suma, estas teorias afirma que as propriedades dos termos morais e suas condições de verdade não são dada pelo agente moral, isto é, constituem esta ordem independente de valoras.

Por sua vez, teorias construtivista defendem que os fatos são construídos por evidência (evidence-dependent). Por isso, tanto as verdades morais são evidence-dependent, quanto os julgamentos morais são de dependência mental do agente. Modelos mind-dependent são modelos em que as condições de verdade dos julgamentos morais evocam afirmações contrafactuais sobre a escolha dos agentes em circunstâncias hipotéticas de algum tipo. Como dito, o construtivismo é um tipo de defesa mind-dependent ao sustentar que a verdade dos julgamentos morais depende de saber se eles (os julgamentos) estão coerentemente relacionados com princípios morais endossados por agentes valorantes engajados em um processo idealizado de raciocínio. ${ }^{45}$ Se assim for, a tese (6) não poderá ser afirmada pelo construtivista, pois implicaria em contradição. Como dito, se Copp assume a forma robusta de realismo (endossando a tese 6), segundo a qual a realidade moral é fixada independentemente de qualquer crença do agente relacionada a ela, a aplicação do construtivismo seria redundante.

Resta perguntar: Como Copp enfrenta esse dilema em sua teoria? Como vimos, ele identifica na paisagem moral a necessidade de que os juízos normativos possuam condições robustas de verdade, assim como a determinação destas condições. Além disso, parece que precisamos determinar, em algum momento, uma espécie de salto normativo das propriedades naturais para propriedades morais, o que nos inclina a pensar

${ }^{45}$ Cf. COPP, 2013, p. 115. 


\section{Dossiê Naturalismo, Dissertatio - Volume Suplementar 02 | UFPel [2015]}

no construtivismo como a metodologia adequada. Podemos assumir o construtivismo restritivista e seu uso procedimental, o qual define as condições que produzirão fatos ou verdades morais como resultado (output). Com isso, tais fatos ou verdades, e somente estes, serão fatos ou verdades morais porque oriundos do procedimento. Em outras palavras, o procedimento oferece as condições de justificação para as proposições morais, embora não explique o tipo de fato ou verdade resultante em termos de objetividade moral. O que sabemos é que o construtivismo sustenta que os fatos morais são determinados como resultado de um procedimento a partir de uma ordem dependente de valores, por isso ele aceitaria a forma ampla de realismo (basic realism) sem contradição, ou seja, endossaria as teses (1) a (5) destacadas por Copp. Esta seria uma interpretação procedimental da teoria original de SCT, onde alguns juízos estariam justificados como códigos sociais morais.

Do mesmo modo, se assumirmos o modelo de Copp como um tipo de construtivismo metaético - considerando-se a questão mind-dependece para a questão normativa e a consequente visão de que não existe uma ordem independente de valores do ponto de vista prático - ainda assim sua teoria endossaria uma dependência contrafactual do valor sobre as atitudes dos agentes valorantes. Em ambas as formas de construtivismo (procedimental ou metaético), a consideração essencial é que não existem fatos morais para além do ponto de vistas dos agentes que valoras a partir da Society-Centered. Logo, toda regra moral social seria criada e justificada a partir desta ponte; antes disso, propriedades naturais não possuiriam o peso normativo suficiente de ser também uma propriedade moral justificada. Per si, SBT apenas oferece as condições de verdade das proposições normativas enquanto uma teoria cognitivista da linguagem normativa, a qual necessita da condição de $S B T$ para oferecer um tipo de justificação para códigos morais 
sociais. Ora, isso parece indicar para a construção moral.

\section{Considerações finais}

Feitos estes esclarecimentos, acredito termos elementos suficientes para considerar a relação entre o construtivismo e o naturalismo em David Copp a partir de uma base comum: o realismo moral. Como mencionado, o naturalismo moral de Copp adiciona uma sexta tese ao realismo básico: (6) proposições morais são proposições naturais. Se Copp admite que o seu naturalismo realista vai ao encontro do construtivismo, a tese acima o colocará em uma encruzilhada. Se admite as similaridades entre naturalismo e construtivismo, então seu realismo não pode recorrer a tese mind-inpendence presente (6). Se o fizer, ele tornaria o construtivismo irrelevante em sua teoria do ponto de vista de justificação. Entretanto, a proposta naturalista de Copp indica que propriedades morais podem ser entendidas enquanto propriedades naturais. Nesse caso, parece que o construtivista pode endossar a posição naturalista de um realismo básico desde que a construção determine o que são fatos ou verdades morais.

O fato é que o recurso a Society-Centered Thery parece indicar para uma forma de naturalismo construtivista na proposta do autor ${ }^{46}$, pois ao admitirmos a exigência de um justificação racional (rationally required) para regras morais, o correto e o incorreto não estão definidos de antemão. Em outras palavras, o código moral ideal seria o código moral que a sociedade racionalmente escolheria usá-lo como código moral social, tendo em vista as necessidades e valores da sociedade, bem como as suas circunstâncias. Se todo os membros da comunidade se subscrevem a ele, então o código moral ideal determina quais ações podemos considerar erradas ou corretas com relação a esta sociedade, o que parece revelar um gosto relativista em sua

${ }^{46}$ COPP, 2007, p. 18-21. 


\section{Dossiê Naturalismo, Dissertatio - Volume Suplementar 02 | UFPel [2015]}

teoria.

Agora, se a opção construtivista acima apresentada não é suficiente, Copp pode ainda assumir o construtivismo metaético como compatível com o realismo em sua teoria, inclusive aceitando suas 5 teses sobre o realismo. Entretanto, a sombra da sexta tese continua pairando em sua teoria. Nesse caso, o construtivismo metaético alega que os fatos normativos são constituídos por fatos implicados a partir de regras da razão prática, os quais são combinados com fatos não-normativos. O truque seria oferecer um modelo plausível de regras da razão prática, o que implica explicar o que envolve jogar o jogo da valoração (playing the game of valuing).

Meu intuito, neste pequeno esboço, não foi defender reivindicações construtivistas em Copp, mas tentar esclarecer pontos obscuros sobre o tema ao longo de sua teoria naturalista, já que a relação entre naturalismo e realismo não é um ponto de discórdia. Se Copp tem êxito no seu desiderato normativo de integrar bases naturais a um modelo construtivista, restaria saber até que ponto o comprometimento com o mundo natural afeta de modo negativo a condição mind-dependence do construtivista, pois a naturalização da moral faz com que as explicações normativas decorram de explicações científicas. Extrapolando esta relação, não parece ser um fato relevante, do ponto de vista de ter razões normativas para a ação, conhecer dados científicos para o que consideramos uma boa vida ${ }^{47}$. Reduções na resposta sobre o código moral social torna os fatos sobre o que é valioso refém do resultado de processos causais que podem ser irrelevantes para a justificação moral. Isso se deve ao fato de que, como no exemplo citado sobre o assassinado, a condição moral de uma ação não passa pela explicação

\footnotetext{
${ }^{47}$ Afirma ela: "By this I mean that putting aside deep philosophical worries about the nature of rulefollowing (no small matter), facts about what a given rule entails in combination with the nonnormative facts do not seem naturalistically puzzling in at all the same way as do facts about how one ought or has most normative reason (full stop) to live." (STREET, p. 16)
} 
científica da regra a partir da causa mortis da vítima. Nesse sentido, percebemos que esta redução de propriedades morais a propriedades naturais decorre da resposta dos agentes sob circunstâncias idealizadas, tal como SCT. Nesse caso, a pergunta é sobre normatividade e não sobre moral. Quando o eixo da discussão é deslocado e a pergunta central é obscurecida, corremos o risco de reduzir não apenas propriedades morais a propriedades naturais, mas também reduzir o âmbito moral ao normativo. Nesse caso, não estaríamos mais nos perguntando se a regras morais, tais como as regras do xadrez ou do beisebol são boas regras, mas sim porque devemos observá-las quando jogamos. Mesmo que as críticas antirrealistas tenham sido refutadas em um nível mínimo, ainda assim admitir uma forma de moral naturalizada não abandona velhos embaraços, na medida em que apresentar um conjunto de dados factuais para explicar o valor de determinado juízo moral não parece ser suficiente para desmistificar a natureza do juízo moral. Este é o problema de não admitirmos a condição construtivista na teoria de Copp. Sem ela, permanecemos com o mistério.

\section{REFERÊNCIAS}

BLACKBURN, Simon. Essays in Quasi-Realism, New York: Oxford University Press, 1993.

. "Anti-realist Expressivism and Quasi-realism." In: COPP, D.

The Oxford Handbook of Ethical Theory Oxford: Oxford University Press, 2006, p. 146-162.

COOP, D. "Is constructivism an alternative to moral realism?" In: BAGNOLI, Carla (ed.) Constructivism in Etbics. Cambridge: Cambridge University Press, 2013, p. 108-132.

. Morality in a Natural World: selected essays in metaetbics. Cambridge: Cambridge University Press, 2007. . Morality, Normativity, and Society. New York: Oxford University Press, 1995. 
DARWALL, S.; GIBBARD, A.; RAILTON, P. "Toward Fin de siècle Ethics: Some Trends." Philosophical Review 101 (1992): 115-189. Reprinted in Moral Discourse and Practice: Some Pbilosophical Approaches. Eds. Stephen Darwall, Allan Gibbard and Peter Railton. Oxford: Oxford UP, 1997. 3-47.

HARMAN, G."Naturalism in Moral Philosophy," Ethical Naturalism: Current Debates, edited by Susana I. Nuccetelli and Gary Seay (Cambridge University Press, 2012), pp. 8-23.

HUME, D. Enquiry concerning Humen Understanding. Trad. T. L. Beauchamp. Oxford: Oxford University Press, 1999.

JACKSON, F. From metaphysics to ethics: a defense of conceptual analysis. Oxford: Clarendon Press, 1998.

KORSGAARD, Christine. The Sources of Normativity. Cambridge: Cambridge University Press, 1996.

Philosophy." "Realism and Constructivism in Twentieth-Century Moral and Moral Psychology. New York: Oxford University Press, 2008, p. 302326.

O'NEILL, Onora. “Constructivism in Rawls and Kant." In: FREEMAN, S. (Ed.). The Cambridge Companion to Rawls. Cambridge: Cambridge University Press, 2003, p. 347-367.

RAWLS, John. "Kantian Constructivism in Moral Philosophy" (1980). In: Collected Papers. Ed. S. Freeman. Cambridge: Harvard University Press, 1999, p. 303-358.

SHAFER-LANDAU, Russ, 2003, Moral Realism: A Defence, Oxford University Press.

STREET, Sharon. "A Darwinian Dilemma for Realist Theories of Value," In: Philosophical Studies 127(1), 2006, p. 109-166.

. "Constructivism about Reasons." In: Oxford Studies in

Metaethics 3, 2008a, p. 207-245.

. "Reply to Copp: Naturalism, Normativity, and the

Varieties of Realism worth Worrying About" In: Philosophical Issues 18(1), 2008b, p. 207-228.

. "What is Constructivism in Ethics and Metaethics?" In:

Philosophy Compass 5, 2010, p. 363- 384. 


\section{Evandro Barbosa}

PUTNAM, H. The collapse of the factu/value dichotomy and other essays. Cambridge: Harvar University Press, 2002. 